\title{
Desenvolvimento Humano e teoria bioecológica: ensaio sobre "O contador de histórias"
}

\author{
Marluce Auxiliadora Borges Glaus Leão \\ Universidade de Taubaté - Taubaté - SP \\ Zilda Regina de Souza \\ Universidade de Taubaté - Taubaté - SP \\ Maria Aparecida Campos Diniz de Castro \\ Universidade de Taubaté - Taubaté - SP
}

\section{Resumo}

Este ensaio apresenta reflexões sobre o processo de desenvolvimento humano, à luz da Teoria Bioecológica, a partir da narrativa fílmica de "O contador de histórias", produção brasileira baseada em história real. Focaliza o desenvolvimento de uma pessoa, as interações entre aspectos multidirecionais de sua trajetória de vida, em contextos próximos e distantes. Utiliza a trama para articular os elementos centrais desta teoria- pessoa, processo, contexto e tempo. Identifica a importância da educação balizando a formação do ser humano diante do fenômeno da violência, mobilizando o processo de resiliência e modulando influências recíprocas no desenvolvimento. A inter-relação entre as características biopsicológicas do protagonista, os processos de socialização e as vulnerabilidades dos contextos em que transita, realça o papel da família e das instituições sociais na construção de sua história. Embora constitua um exemplo metafórico, permite uma leitura empírica da vida.

Palavras-chave: Desenvolvimento humano; filmes; experiências de vida.

\section{Human development and bio-ecological theory: essay on "The Storyteller"}

\begin{abstract}
This paper presents reflections about human development process in the light of Bioecological Theory from the film narrative of "The Storyteller," Brazilian production based on real history. Focuses on the development of a person, the interactions between multidirectional aspects of his life story, in close and distant contexts. Uses the plot to articulate the core elements of this theory - person, process, context and time. Identifies the importance of education managing the formation of the human being on the phenomenon of violence by mobilizing the process of resilience and modulating reciprocal influences on development. The interrelationship between the bio-psychological characteristics of the protagonist, socialization processes and vulnerabilities in contexts in which transits, enhances the role of the family and social institutions in the construction of its history. Although it is a metaphorical example, allows an empirical reading of life.
\end{abstract}

Keywords: Human development; motion pictures; life experiences.

\section{Desarrollo humano y teoría bioecológica: ensayo sobre "El contador de historias"}

\section{Resumen}

Este ensayo presenta reflexiones sobre el proceso de desarrollo humano, a la luz de la Teoría Bioecológica, a partir de la narrativa fílmica de "El contador de historias", producción brasileña basada en historia real. Focaliza el desarrollo de una persona, las interacciones entre aspectos multidireccionales de su trayectoria de vida, en contextos cercanos y distantes. Utiliza la trama para articular los elementos centrales de esta teoría- persona, proceso, contexto y tiempo. Identifica la importancia de la educación balizando la formación del ser humano delante del fenómeno de la violencia, movilizando el proceso de resiliencia y modulando influencias recíprocas en el desarrollo. La inter-relación entre las características biopsicológicas del protagonista, los procesos de socialización y las vulnerabilidades de los contextos en que transita, subraya el papel de la familia y de las instituciones sociales en la construcción de su historia. Aunque constituya un ejemplo metafórico, permite una lectura empírica de la vida.

Palabras clave: Desarrollo humano; película; historia de vida. 


\section{Introdução}

O filme "O contador de histórias" (Vilaça, 2009) é uma produção cinematográfica nacional do ano de 2009 e retrata a biografia de um educador brasileiro, hoje adulto, a partir dos contextos em que se desenvolveu - desde sua infância até a idade adulta. De forma ilustrativa mostra o processo de socialização de uma criança no início da década de 1980 , em Belo Horizonte, MG, Brasil; sua interação com os diversos contextos de desenvolvimento, da família de origem a uma instituição socioeducativa e à rua, até conquistar uma "nova família".

Sua trajetória de vida é permeada pela interação de aspectos de vulnerabilidades múltiplas, que agem como potenciais elementos na sua formação e ao final, possibilitam a formação de um adulto bem-sucedido. A trama desta história demonstra a complexidade das influências recíprocas desses elementos contextuais no seu processo desenvolvimentista, cuja transformação da pessoa convida e permite um ensaio de compreensão a partir de quadros conceituais diversos.

A Teoria Bioecológica de desenvolvimento humano foi aqui eleita como aporte para a leitura aproximativa da narrativa deste filme e diálogo com as seguintes questões: Como se dá o desenvolvimento humano ao longo da vida, mediante contextos adversos? Quais as características que orientam o desenvolvimento na proposta Bioecológica? Assim, faz-se uma breve incursão a esta teoria para, posteriormente, articulá-la à história narrada no filme.

\section{A Teoria Bioecológica em questão}

No final da década de 1970 Bronfenbrenner publicou seu estudo, inicialmente chamado Teoria Ecológica, que privilegiava uma compreensão de desenvolvimento de forma contextualizada e em ambientes naturais, visando apreender a realidade de forma mais abrangente, tal como é vivida e percebida pela pessoa no contexto em que se insere (Bronfenbrenner, 1977/1996). Ao reformular sua teoria para uma compreensão bioecológica do desenvolvimento humano, passou a ressaltar, além da interdependência indivíduocontexto, as características da pessoa em desenvolvimento em relação às influências de quatro aspectos multidirecionais inter-relacionados, que constituem o modelo PPCT - pessoa, processo, contexto e tempo - elementos centrais da Teoria Bioecológica (Bronfenbrenner, \& Morris, 1998).

Conforme Martins e Szymanski (2004) neste modelo, pessoa refere-se ao fenômeno de constâncias e mudanças ao longo da vida, características do indivíduo em desenvolvimento, como convicções, nível de atividade, temperamento, metas, motivações, gênero, entre outras. O processo diz respeito à participação ativa em interação progressivamente mais complexa, recíproca com pessoas, objetos e símbolos no ambiente imediato, ocorrendo de forma regular e duradoura. Por contexto, entende-se o ambiente em que a pessoa está inserida (micro, meso, exo e macrossistemas) e onde se desenrolam os processos desenvolvimentais, desde os mais imediatos até os mais remotos, sujeitos a influências recíprocas.

O tempo refere-se às pressões exercidas sobre a pessoa pelas mudanças que ocorrem ao longo do seu curso de desenvolvimento em virtude de eventos históricos a que está exposta, seja na família ou em um contexto mais amplo. As mudanças constituem-se como elementos propulsores de transformações.

Como contexto bioecológico mais imediato, o microssistema representa os locais onde ocorrem as interações face a face, cada vez mais complexas, como a família, o trabalho ou a escola, sendo "[...] constituído por padrões de atividades, papéis e relações interpessoais experienciados pelos indivíduos em um dado ambiente, no qual suas características físicas, sociais e simbólicas particulares funcionam de maneira a estimular ou inibir as relações interpessoais." (Polônia, Dessen, \& Silva, 2005, p.79).

Enquanto o mesossistema refere-se às inter-relações entre dois ou mais microssistemas em que a pessoa está envolvida e participa de forma ativa, o exosistema, ao contrário, compõe-se de um ou mais ambientes em que a pessoa não participa diretamente, contudo, "os acontecimentos nesses ambientes afetam ou são afetados pelo ambiente onde se encontra a pessoa em desenvolvimento" (Polônia \& cols, 2005, p.81). Já o macrossistema, "envolve todos os ambientes, formando uma rede de interconexões que se diferenciam de uma cultura para outra" (Martins \& Szymanski, 2004, p.67) representando os ambientes mais remotos como a cultura, etnia ou classe social.

$\mathrm{Na}$ Teoria Bioecológica, a ênfase recai sobre as características biopsicológicas da pessoa e suas formas particulares de interação ao longo do tempo, engendrando o denominado "processos proximais" como mecanismos primários que produzem o desenvolvimento humano (Bronfenbrenner \& Morris, 1998).

Para uma compreensão da dinâmica dos aspectos que afetam o desenvolvimento nessa teoria, esta análise toma o roteiro do filme como elemento empírico de proposições que, ao retratar a biografia do protagonista - Roberto, e a cronologia dos eventos do seu desenvolvimento, discute a inter-relação entre os diversos contextos (microssistema, mesossistema, exossistema e macrossistema), tal como os "fenômenos que ocorrem em ambientes de vida real estão sempre sujeitos a variadas formas de influências, que podem variar ao longo do tempo e do espaço" (Bronfenbrenner, 1996 conforme citado por Martins \& Szymanski, 2004, p.72).

Esses contextos são vistos como contextos de formação e compreendidos na perspectiva das sociedades ocidentais como a participação das pessoas em diferentes práticas educativas ao longo de suas vidas, "aprendendo os princípios da cultura à qual pertencem [...] que lhes permitem diversificar as suas relações, assumir diferentes papéis, aprender padrões de comportamento e de relacionamento diversos (Salvador, Mestres, Gõni \& Gallart,1999, p.195). 


\section{A linguagem fílmica como} estratégia metafórica de compreensão do

\section{desenvolvimento humano}

É possível assinalar, de início, que os elementos contextuais da trajetória de vida de Roberto são permeados pela violência de variadas formas e nos diferentes contextos. Violência aqui entendida de acordo com a concepção da Organização Mundial da Saúde $(2002$, p.5) como um fenômeno caracterizado pelo

[...] uso intencional da força física ou do poder, real ou em ameaça, contra si próprio, contra outra pessoa, ou contra um grupo ou uma comunidade, que resulte ou tenha a possibilidade de resultar em lesão, morte, dano psicológico, deficiência de desenvolvimento ou privação.

Embora o filme retrate apenas alguns acontecimentos da vida familiar de Roberto quando criança, há indicativos de um contexto marcado por dificuldades socioeconômicas. A única referência à figura paterna é de que estava desempregado, cabendo à mãe trabalhar como lavadeira para cuidar da sobrevivência dos nove filhos. Essa mãe sugere diligência e competência nesse cuidado, estabelecendo as díades de desenvolvimento com Roberto, considerando os limites de suas condições objetivas de vida.

No modelo bioecológico original, esta formação de díades nas relações interpessoais, segundo Martins e Szymanski (2004), ocorre quando um dos membros da dupla recebe influência do outro no seu processo de desenvolvimento. As díades podem ser observacionais (quando um membro observa cuidadosamente o outro), de atividade conjunta (quando duas pessoas se percebem fazendo algo juntas) e a primária (quando mesmo distantes um influencia o outro). São essenciais à formação dos processos proximais como "formas particulares de interação entre organismo e ambiente, que operam ao longo do tempo e compreendem os primeiros mecanismos que produzem o desenvolvimento humano" (Bronfenbrenner \& Morris, 1998, p.994).

Todavia, esses processos requerem "[...] a necessidade de constância e regularidade de tempo para que o curso do desenvolvimento saudável (ou não) se estabeleça [...] Ambos os protagonistas são recursivamente importantes um para o desenvolvimento do outro" (Bronfenbrenner, 2005 citado por Eschiletti Prati, \& cols., 2008, p.164).Cumpre à família fomentar "[...] o processo de socialização, a proteção, as condições básicas de sobrevivência e o desenvolvimento de seus membros no plano social, cognitivo e afetivo" (Dessen, \& Polônia, 2007, p.22), sendo notável sua interferência na vida das pessoas, conforme atestam diferentes autores citados por Faco e Melchiori (2009, p.121):
Família representa o espaço de socialização, de busca coletiva de estratégias de sobrevivência, local para o exercício da cidadania, possibilidade para o desenvolvimento individual e grupal de seus membros, independente dos arranjos apresentados ou das novas estruturas que vêm se formando. Sua dinâmica é própria, afetada tanto pelo desenvolvimento de ciclo vital, como pelas políticas econômicas e sociais.

Nesta história, frente às dificuldades impostas pelo cotidiano nos anos de 1980, o imaginário social da mãe de Roberto sucumbe à sedução da mídia televisiva que chegava à grande parte da população. À época, a FEBEM (Fundação Estadual do Bem-estar do Menor) ${ }^{1}$, instituição brasileira implantada em vários estados do País, com caráter socioeducativo, veiculava uma propaganda que emanava sua ideologia ${ }^{2}$ de assistência infanto-juvenil como forma de superação da miséria, garantia da formação moral, escolar e profissional em carreiras promissoras.

Para essa mãe, a FEBEM representava a esperança de oferecer um futuro digno aos filhos, ao menos ao caçula, escolhido dentre os demais para ser um "doutor". Alimentada pela crença de que seu filho estaria mais bem cuidado na instituição que no seio familiar, ela entrega Roberto aos cuidados do Estado. É possível observar o comportamento de apego $^{3}$ da criança em relação à mãe resistindo à separação e a família como instância de socialização desconsiderada pela possibilidade de segurança e ascensão social "prometida" por outro microssistema.

A sequência de eventos na história de vida de Roberto passa a confrontar seu potencial de resiliência ${ }^{4}$ para sobreviver aos inúmeros riscos a que esteve exposto nos diferentes sistemas, que acenavam sequelas irreparáveis. A violência institucional da antiga FEBEM, como microssistema, repercute como efeito cascata, pois, conforme Bronfenbrenner (2005) o ser humano é

[...] um ser biológico e psicológico, interage constantemente com seu contexto e é produto deste processo de interação. Bronfenbrenner usou o termo interação com uma

1 FEBEM/MG (Fundação Estadual do Bem Estar do Menor) entidade criada pelo governo de Minas Gerais na década de 1970, extinta legalmente em 1995 e fechada plenamente em janeiro de 2004. Conhecida como Centro Educacional do Horto de Belo Horizonte e, pejorativamente, como "boca aberta", não tinha critérios rigorosos para a internação e as fugas e reincidência de internações eram rotineiras (Viegas, 2007).

2 Ideologia - compreendida como um "conjunto de representações e ideias, bem como as normas de conduta, por meio das quais o indivíduo é levado a pensar, sentir e agir da maneira que convém à classe que detém o poder" (Aranha,\& Martins, 1998, p.72).

3 Apego - refere-se a um tipo de vínculo no qual o senso de segurança de alguém está estreitamente ligado à figura de apego (Bowlby, 1979/1997).

4 Optou-se por definir resiliência como "capacidade de responder de forma mais consistente aos desafios e dificuldades, de reagir com flexibilidade e capacidade de recuperação diante dos desafios e circunstâncias desfavoráveis, tendo uma atitude otimista, positiva e perseverante, e mantendo um equilíbrio dinâmico durante e após os embates" (Placo, 2001,pp.7-8). 
conotação espiral, multicausal e processual. Ou seja, o desenvolvimento humano ocorre através de ampliações e aproximações entre a pessoa e os diversos elementos do contexto que se influenciam mutuamente de forma não linear e dinâmica, alterando-se qualitativamente ao longo do tempo. (Bronfenbrenner, 2005 conforme citado por Eschiletti Prati \& cols., 2008, p.161).

Este novo contexto exerce influência sobre seu desenvolvimento humano desconstruindo suas fantasias infantis e esperançosas sobre o mundo e favorecendo um espectro de reações frente ao não atendimento de suas necessidades básicas, como segurança. Pelas dificuldades de vida cotidiana da mãe de Roberto as visitas foram escasseando e os vínculos fragilizando-se, além de sua possível percepção da transformação dos comportamentos do filho, como indiferença ao seu contato.

É fato corrente na literatura que a situação de acolhimento ${ }^{5}$ geralmente agride crianças e adolescentes com consequências graves, podendo comprometer sua formação.

Umas reagem com amortecimento afetivo como defesa, criando uma casca protetora sobre seu verdadeiro self, para aplacar o sofrimento vivido. Outras evidenciam intensa excitabilidade, agressividade e agitação, mescladas à erotização precoce da conduta. Nelas, tudo parece girar falso, expressando desta forma o sentimento de vazio e de desesperança (Carvalho, Montesi, \&Gonçalves, 2006, p.157).

Apesar da história datada, salienta-se a atualidade desta temática, a importância dos aspectos do macrossistema na realidade vigente dos abrigos brasileiros, em que há muito a avançar, de acordo com os dados do IPEA - Instituto de Pesquisa Econômica Aplicada, referidos pelo Fundo das Nações Unidas para a Infância - UNICEF (n.d., p.120) sobre uma pesquisa em 589 instituições de acolhimento representando mais de 20 mil abrigados:

O levantamento mostrou que $86,7 \%$ dos abrigados possuem família, sendo que $58,2 \%$ mantêm o vínculo com elas e $22,7 \%$ não mantêm. Apenas $4,6 \%$ realmente não têm parentes e $5,8 \%$ possuem impedimento judicial para a manutenção do vínculo. $\mathrm{O}$ grande percentual de crianças e adolescentes que possui família e mantém o vínculo acaba, no entanto, privado da convivência familiar pela ausência de programas de convivência. Dos 589 abrigos pesquisados, apenas 39 - uma parcela ínfima de 6,6\% - realizam ações nesse sentido. O resultado do descaso é assustador: $55,2 \%$ dos abrigados estão institucionalizados há um período que varia de sete meses a cinco anos. Desse total, $32,9 \%$ vivem dessa forma entre dois e cinco anos (UNICEF, n.d., p. 120).

5 Ressalta-se que, conforme explicitado no filme, a Febem de Minas Gerais acolhia as crianças e adolescentes. Atualmente essa função é exercida pelas diversas instituições de acolhimento sob a supervisão do Estado após decisão judicial.
Este sistema de acolhimento institucional do Brasil não revela um contexto de desenvolvimento promissor por tornar-se, para além de lar transitório, a casa de muitas crianças e adolescentes vítimas de um sistema falido que reproduz a violência sobrepondo-se, assim, à falta de proteção da família e da comunidade. Uma vez sem o abrigo familiar, os institucionalizados são reduzidos a um número.

As crianças quando albergadas em ambiente inóspitos sentem repetidamente usurpadas com o desaparecimento inesperado de seus bens pessoais, com as trocas inexplicáveis de camas e de dormitórios, mudanças que interferem no seu ritmo do sono e alimentação. Ao mesmo tempo lastimam a imposição quanto ao uso de vestimentas, aos cuidados impessoais que lhes são devotados em nome da organização institucional (Carvalho, Montesi, \& Gonçalves, 2006, p.151).

É importante destacar que o Conselho Nacional dos Direitos das Crianças e dos Adolescentes e Conselho Nacional da Assistência Social (2008) lançou publicação elencando as diretrizes técnicas para o acolhimento institucional de crianças e adolescentes e um de seus princípios prevê a excepcionalidade do afastamento do convívio familiar.

Ao completar sete anos, de acordo com a política socioeducativa da FEBEM à época, Roberto é transferido internamente para outro "projeto", começando a conviver com internos entre sete e catorze anos. Tal mudança abrupta significa a perda da inocência infantil, pois exige que ele desenvolva comportamentos e habilidades mais complexos para a garantia de sua sobrevivência. Ressalta a importância desta dimensão contextual e temporal sobre os aspectos individuais repercutindo em seu desenvolvimento e também os influenciando, conforme salientam Bronfenbrenner e Morris (1998, p.66).

Eventos históricos podem alterar o curso do desenvolvimento humano em qualquer direção, não só para indivíduos, mas para segmentos grandes da população. A passagem de tempos em termos históricos tem efeitos profundos em todas as sociedades. Esta dimensão contexto e tempo em um macrossistema pode ser ilustrada pelo advento do Estatuto da Criança e do Adolescente (ECA) (Lei n. 8069,1990) que substituiu o Código de Menores (Brasil, 1979) e se consolidou como elementar no tratamento às questões da criança e do adolescente no Brasil. O ECA admite a criança e o adolescente como sujeitos de direitos ${ }^{6}$ visando assegurar seu desenvolvimento priorizando políticas como observado em seu $3^{\circ}$ artigo:

A criança e o adolescente gozam de todos os direitos fundamentais inerentes à pessoa humana, sem prejuízo da proteção integral de que trata esta Lei, assegurando-seIhes, por lei ou por outros meios, todas as oportunidades e

6 Lembra-se que no âmbito dos direitos humanos de crianças e adolescentes houve seu reconhecimento como pessoa - no político, como cidadão e no jurídico, como sujeito de direitos (Théry, 1991 conforme citado por Caliman, 2006, p. 385). 
facilidades, a fim de Ihes facultar o desenvolvimento físico, mental, moral, espiritual e social, em condições de liberdade e de dignidade (Lei n. 8069, 1990).

Contudo, a "odisséia" do protagonista deste filme é anterior à aprovação deste mecanismo social, demarca um tempo e contexto cujas crianças e adolescentes vulneráveis eram marginalizados pela sociedade e pelo sistema legal. Esta história e de tantas outras crianças e adolescentes vítimas desta violência social e institucional, mesmo após a aprovação do ECA, remonta a questões endógenas na cultura brasileira; reflexos de um macrossistema marcado por uma história de dominação e exclusão influenciando o desenvolvimento humano. Em relação aos cuidados daqueles que precisam, imperam paradigmas arcaicos conforme documenta o UNICEF (n.d., p.119).

Essa negligência consiste no descuido, desleixo por parte da instituição, má qualidade de suas instalações físicas, carência de pessoal e, entre outras características, ausência de processo educativo. Falamos, portanto, da ação ou omissão que deixa de atender às necessidades básicas da criança e do adolescente e os direitos previstos no Estatuto da Criança e do Adolescente-ECA.

Sem o amparo da família e ou de qualquer outro sistema, crianças e adolescentes como Roberto tendem a refugiar-se nas ruas, experimentam a liberdade e sustentam um ciclo de violência, conforme atesta o Mapa da Violência IV: Os Jovens do Brasil, elaborado para a UNICEF (n. d., p. 123, grifo nosso) pelo sociólogo Júlio Jacobo Waiselfisz, a partir de fontes oficiais e recolhidos no período de 1993 a 2002, indicando

[...] dados preocupantes em relação à faixa da população com idade entre 14 e 25 anos. Segundo ela [a publicação], em 1993 a taxa de homicídios contra jovens era de 34,5 homicídios em 100 mil, já maior que a relativa à da população em geral (20,3 para $100 \mathrm{mil})$. Em 2002, essa taxa aumentou drasticamente para 54,7 em cada 100 mil. Embora o período mais crítico seja aos 20 anos, quando a taxa de homicídios é de 69,1 por 100 mil, as taxas dos 15 aos 18 anos são igualmente assustadoras (UNICEF, n.d., p.123)

Neste cenário, a banalização da vida humana é evidenciada, sobretudo pelos jovens que buscam nas drogas e nas práticas ilícitas mecanismos para a sobrevivência. Quando internos em instituições como a FEBEM, tornam-se vítimas de um sistema falido - "fogem e são recapturados". Como a maioria desses, Roberto também fugiu e foi recapturado diversas vezes, afinal, "a vida na rua, muitas vezes, representa a melhor alternativa encontrada pelas crianças que sofrem algum processo de vitimização, seja na família de origem ou na sociedade." (Paludo, \& Koller, 2005, p. 191).

A condição para ser aceito nos grupos da rua, no entanto, mostra-se perversa. Roberto vivencia essa questão ao descobrir-se admirando o líder de um desses grupos, cuja participação almeja, mas para se (re)conhecer torna-se vítima de abusos diversos. Assim, as atividades e interações cotidianas nas quais participa regularmente influenciam seu desenvolvimento. É possível pensar ainda, que o fato de Roberto desejar se parecer com seu ídolo, o que remete à questão da sua formação identitária, envolve "ao mesmo tempo aquilo que torna semelhante e diferente, único e igual aos outros" (Chamon, 2003, p.8); a necessidade de pertencimento e reconhecimento em um sistema (micro, meso ou exo) no processo de construção da identidade pessoal.

Este ir e vir de interações entre os vários ambientes configura-se o mesossistema influenciando o desenvolvimento e vice-versa. Dessa forma, o protagonista passa a interagir ativamente entre dois ou mais ambientes, "podendo ser formado ou ampliado sempre que ela (a pessoa) passe a fazer parte de novos ambientes." (Martins, \& Szymanski, 2004, p.67).

Nesta migração entre sistemas constata-se que Roberto foi constituindo novos processos proximais, ou seja, relações entre pessoas, objetos e símbolos, fazendo com que esta "transição ecológica" fosse significada, mesmo sendo passageira entre os diversos ambientes. Sobre os riscos no desenvolvimento de crianças e adolescentes que vivem na rua, Santos e Dell 'Aglio (2006, p. 222), alertam que elas "[...] têm um tempo mínimo para tornar significativas suas relações no espaço físico e social da rua, constituindo processos, construindo as suas histórias e se caracterizando como pessoas".

A discussão de Santos e Dell 'Aglio (2006) sobre o constructo da resiliência na situação de rua, o que é saudável ou não, adaptativo ou inadaptativo, permite pensar que a trajetória de Roberto exigia muito de seu processo de resiliência frente aos riscos psicossociais da rua, considerando, sobretudo, tratar-se de uma criança que, supostamente, não tinha dimensão dos riscos aos quais se expunha.

Em cena emblemática de sofrimento após uma série de abusos físicos e psíquicos, Roberto tenta dar cabo à própria vida, confrontando seus limites de enfrentamento das adversidades. Surge, nesse momento, Margherith Duvas, pedagoga e pesquisadora francesa, como uma figura de um outro que reativa seu lado virtuoso, fomenta a qualidade de um encontro que resulta na catalização dos aspectos positivos que Roberto possui, instigando seu processo de formação,investe na aproximação, vendo-o como potencial sujeito de sua pesquisa.

Conforme relato de Roberto, este primeiro contato causou-lhe estranhamento, pois nunca ninguém se aproximara dele com tamanha educação. A partir desta cena do filme há indícios do início de uma díade potencial de desenvolvimento humano, ou seja, do processo que ocorre a partir da relação de atenção estabelecida pela pessoa em uma dada atividade junto ao outro.

Sua relação com a pesquisadora fortalece a formação de processos proximais, aponta uma progressiva interferência no seu desenvolvimento. É fato que ela o tem como sujeito de pesquisa, todavia, passa a atuar como um suporte ("familiar ideal", talvez) mobilizando seus aspectos sadios, 
habilidades potenciais como seu senso de imaginação. Passa a significar segurança física, social e psíquica - continuar vivo, romper com a violência cotidiana, ter um lar, aprender valores éticos, ser alfabetizado, vencer seus medos e preconceitos, (re) conhecer seu potencial, interagir com a cultura de outro país, amar e ser amado - possibilidades que mais tarde o formarão como "doutor da vida", desejo de sua mãe.

Sobre esta questão, Yunes (2003, p.81) em reflexões sobre o conceito de resiliência, cujo discurso hegemônico foca o indivíduo, chama a atenção sobre a importância de pesquisar e compreender os aspectos sadios e de sucesso do grupo familiar sob a ótica ecológica. Faz referências a estudos sobre resiliência com indivíduos, indicando "[...] a influência de relações com pessoas significativas e próximas como apoio na superação das adversidades da vida".

O exossistema como ambiente em que a pessoa em desenvolvimento não participa ativamente, mas pelo qual é afetada, remete à cena do filme em que um adolescente da FEBEM (apelidado de "Cabelinho de fogo" e ídolo de Roberto até então), adentra a casa da pesquisadora onde Roberto estava morando, tentando se integrar a uma nova vida e, talvez, fugir de seu passado. Estabelece-se nesse momento para ele, um conflito entre dois caminhos, uma tensão consciente entre voltar ao grupo e ao modo de vida anteriores, assumindo todas as consequências, ou fazer uma nova história sob outros parâmetros. Roberto escolhe o desafio da nova vida, afinal fora acolhido, física e afetivamente, pela pesquisadora.

A sequência do filme mostra a trajetória de desenvolvimento de uma vida marcada por muitas idas e vindas. Um (re)aprender de limites, do valor e respeito à sua própria vida, a do outro e ao seu entorno; um processo lento de reconhecimento e construção de sua identidade. Indica uma "[...] participação ativa em interação progressivamente mais complexa, recíproca com pessoas, objetos e símbolos no ambiente imediato" (Martins \& Szymanski, 2004, p.66).

Trata-se agora de uma pessoa que pertence a um mundo que faz sentido e que ele passa a atribuir sentidos. llustra a importância das interações sociais duradouras e regulares para adquirir novas habilidades, resolver problemas, executar tarefas complexas, adquirir conhecimentos e experiências novas. Essenciais também são as atitudes de confiança, perseverança e crédito no potencial de desenvolvimento de Roberto, por parte da pesquisadora em direção à re(construção) de sua trajetória de vida.

No final, em outra cena emblemática, uma das educadoras da FEBEM junto à pesquisadora avalia o sucesso da transformação de Roberto, mediante a vigência na instituição de uma "guerra" fadada ao fracasso, que no caso dele fora vencida por questões de sorte. Ela sugere não acreditar no poder da dedicação de um ser humano a outro, do suporte necessário à apreensão das regras e princípios éticos e no papel desempenhado por uma instituição na ausência da família, não consegue atentar que os dilemas humanos são inerentes à convivência, mas que se pode optar em favor da vida, visto o desenvolvimento ser influenciado por ambientes próximos e distantes,
[...] e pela relação mútua entre o ser humano ativo, em desenvolvimento, e as propriedades mutantes dos ambientes em que a pessoa em desenvolvimento vive, conforme esse processo é afetado pelas relações entre estes ambientes e pelos contextos mais amplos em que os ambientes estão inseridos (Bronfenbrenner,1996, p.18).

Tudo indica que esta relação de interdependência duradoura entre Roberto e a pesquisadora configurou díades essenciais na formação dos processos proximais, como potenciais "engrenagens do desenvolvimento, porque é engajando-se nessas atividades e interações que o indivíduo torna-se capaz de dar sentido ao seu mundo, entender o seu lugar neste mundo e, ao mesmo tempo em que nele ocupa um lugar, transforma-o" (Tudge, 2008, p.4). Pode-se pensar ainda que

conhecer e aproveitar o impacto das diversas práticas educativas no desenvolvimento das pessoas exige a análise da potencialidade de cada um e de todos em conjunto. Tanto no âmbito da conceitualização teórica como no do planejamento de políticas em diferentes áreas - na escola, na família, nos meios de comunicação -, bem como na intervenção psicopedagógica, os progressos deverão ser feitos também no terreno da sua inter-relação (Salvador,\& cols., 1999, p.197-198).

Por ocasião da produção do filme, em 2009, Roberto adulto e também pedagogo, assim como o fizera Margherith, envida esforços para influenciar a vida de muitas pessoas, em diferentes sistemas, se transformando também em um contador de estórias (ou histórias). Por meio de seu percurso de vida retratado nesta obra cinematográfica busca mobilizar o potencial de desenvolvimento de pessoas, famílias, escolas, instituições e políticas sociais.

\section{Considerações finais}

Esta história cinematográfica favoreceu ensaiar uma compreensão a partir dos conceitos-chave da Teoria Bioecológica, permitindo pensar sobre a complexidade dos elementos que interagem no processo de desenvolvimento. Conjuga, a exemplo da vida real, o papel dos microssistemas - família, escola-instituição e rua no desenvolvimento dos processos proximais, elementos básicos no processo de socialização e desenvolvimento humano, dessa perspectiva teórica.

A temática central ilustrou uma situação empírica do poder da educação na formação dos indivíduos. A despeito das vivências de inúmeros aspectos de vulnerabilidade quando ainda criança e adolescente constata-se que no confronto entre os limites de resiliência do protagonista, a qualidade da relação diádica desenvolvida entre ele e a educadora Margherith atuou como importante fonte de apoio social e psicológico, fator protetor frente às adversidades em seu percurso de vida. 
Ressalta-se o papel da educação como projeto a edificar-se, quando apoiado entre os vários protagonistas, não apenas circunscritos aos professores ou aqueles que representam o contexto escolar. Neste caso, a atuação de Margherith estimulou processos de desenvolvimento, preparando Roberto para intervir ativamente na sociedade. É sabido que o ser humano é construtor do seu próprio conhecimento, mas é possível reconhecer (e esta história assim o confirma), que nessa tarefa outros podem colaborar no processo de desenvolvimento e de aprendizagem e também serem afetados na interação vivida.

Estas reflexões permitem pensar na problemática que circunda o jovem dos nossos dias. O convite à droga, a coexistência com o desemprego dos pais, a ausência cada vez mais comum de uma das figuras parentais, os fenômenos de discriminação racial e tantos outros problemas fazem parte da sua vida e não podem ser ignorados pela escola como contexto educativo e de produção de análises crítico-teóricas.

Será que os dirigentes das organizações escolares e institucionais, especialmente as formais, estão preocupados com tais questões quando pensam e planejam as ações de natureza pedagógica? Podem eles fundamentar-se na ideia de que é preciso fazer dos contextos educativos, em geral, ambientes facilitadores de aprendizagem e integração da criança e do jovem na vida social, otimizando o dinamismo das suas transformações?

A trajetória de vida retratada reitera a necessidade de preparar formadores que, de fato, se façam educadores e promotores do desenvolvimento humano. Ser formador envolve uma simbiose de competências, de natureza referencial, técnica, operativa, interpretativa e interpessoal, mas principalmente, ser capaz de oferecer contextos interativos de desenvolvimento.

Por fim, na trama dessa história constatam-se as possibilidades de enfrentamento e sucesso no desenvolvimento, mesmo na presença de contextos adversos. Analisada por este ângulo, supera-se a premissa fatalista de que, uma vez vítimas do sistema vigente, não há desenvolvimento possível, embora não se justifique que o Estado deva ser eximido das responsabilidades quanto ao fomento, criação, implementação, análise e monitoramento de políticas sociais e públicas destinadas à infância e a juventude do país. Responsabilidade passível de ser compartilhada entre governantes, sociedade civil e seus cidadãos. Inúmeras histórias como a de Roberto são protagonizadas em todos os "cantos" do Brasil, um país continental; negar sua existência é não desvelar realidades e incorrer em possibilidades de viver em contextos de "faz de conta".

A escolha de ser "cuidado" por Margherith aconteceu mediante dor e sofrimento. Roberto empreendeu esforços para esta pertença, optou por ser cuidado; ao receber as inúmeras influências inerentes à existência humana, superou as adversidades e reinventou sua própria história: "Minha mãe francesa me ensinou que poderia ser ordinário ou extraordinário; esse extra faria toda a diferença" (Vilaça, 2009). Quantos outros terão a mesma sorte? Recorrendo à máxima popular, aqui "a arte imita a vida", mas é possível supor o inverso.

\section{Referências}

Aranha, M. L., \& Martins, M. H. P (1998). Temas de filosofia (4a ed.) São Paulo: Moderna.

Bowlby, J. (1997). Formação e rompimento dos laços afetivos (3a ed.) São Paulo: Martins Fontes (Trabalho original publicado em 1979).

Conselho Nacional dos Direitos das Crianças e dos Adolescentes, \& Conselho Nacional de Assistência Social (2008). Orientações Técnicas para o serviço de acolhimento de crianças e adolescentes. Brasília. Recuperado: 16 set. 2013. Disponível:http://portal.mj.gov. $\mathrm{br} /$ sedh/conanda/documentos/orienta\%C3\%A7\%C3\%B5es_ acolhimento_consulta_publica.pdf

Bronfenbrenner, U. (1977). Toward an experimental ecology of human development.American Psychologist, 32, 513-531. Recuperado: 3 abr. 2013. Disponível: http://www.apa.org/pubs/index.aspx

Bronfenbrenner, U. (1996). A ecologia do desenvolvimento humano: experimentos naturais e planejados. Porto Alegre: Artmed. (Obra original publicada em 1977).

Bronfenbrenner, U., \& Morris, P. A. (1998). The ecology of developmental processes. Em W. Damon, \& R. M. Lerner (Orgs.), Handbook of child psychology. Theoretical models of human development (Vol. 1, 5a ed., pp. 993-1028). New York: John Wiley.

Caliman, G. (2006). Estudantes em situação de risco e prevenção. Ensaio: Avaliação e Políticas Públicas em Educação, 14(52), 383396. Recuperado: 30 set. 2013. Disponível: http://socialeducation. files.wordpress. com/2010/11/caliman-estudantes-risco1.pdf

Carvalho, A. L. A; Montesi, M., \& Gonçalvez, T. E. (2006) Abrigar, desabrigar... um percurso pelas trilhas da delicadeza. In: S. M Oliveira; T. E. Gonçalves (Orgs.) Famílias e Instituições enlaces possíveis. (pp. 145-164). Taubaté: Cabral Editora e Livraria Universitária.

Chamon, E. M. Q. O. (2003). Formação e (re) construção identitária: estudo das memórias de professores do ensino básico inscritos em um programa de formação continuada. Tese de Doutorado, Faculdade de Educação, Universidade Estadual de Campinas-SP.

Dessen, M. A. \& Polônia, A. C. (2007). A família e a escola como contextos de desenvolvimento humano. Paidéia, 17 (36), 21-32. Recuperado: 24 jun, 2013. Disponível: http://www.scielo.br/paideia

Eschiletti Prati, L.; Paula Couto, M. C. P.; Moura, A.; Poletto, M., \& Koller, S. H. (2008). Revisando a Inserção Ecológica: Uma Proposta de Sistematização. Psicologia Escolar e Educacional. 17 (1), 181-184. Acesso em Outubro, 30, 2013, em http://www.scielo. $\mathrm{br} / \mathrm{pdf} / \mathrm{prc} / \mathrm{v} 21 \mathrm{n} 1 / \mathrm{a} 20 \mathrm{v} 21 \mathrm{n} 1 . \mathrm{pdf}$. 
Faco, V. M. G., \& Melchiori, L. E. (2009). Conceito de Família: adolescentes de zona rural e urbana. Em T. G. M. Valle (Org.), Aprendizagem e desenvolvimento humano avaliações e intervenções (pp. 121-154). São Paulo: Cultura Acadêmica.

Fundo das Nações Unidas para a Infância [UNICEF] (n.d.). Violência Institucional: quando o Estado agride a criança. Brazil. Recuperado: 22 ago. 2012. Disponível: http://www.unicef.org/ brazil/pt/Cap_06.pdf

Lei n. 6697, de 10 de outubro de 1979 (1979). Dispõe sobre o Código de Menores. Brasília, DF: Presidência da República. Recuperado: 10 nov. 2012. Disponível: http://www.mp.sp.gov.br/portal/page/ portal/cao_infancia_juventude/legislacao_geral/leg_geral_federal/ LEI_6697_79.HTM

Lei n. 8069 de 13 de julho de 1990 (1990). Dispõe sobre o Estatuto da Criança e do Adolescente. Brasília, DF: Presidência da República. Recuperado: 22 ago, 2010. Disponível: http://www.planalto.gov. br/ccivil_03/Leis/L8069.htm

Martins, E., \& Szymanski, H. (2004). Abordagem ecológica de Urie Bronfenbrenner em estudos com Famílias. Estudos e pesquisas em Psicologia. Recuperado: 14 out. 2013. Disponível: http://www. revispsi.uerj.br/v4n1/artigos/Artigo\%205\%20-\%20V4N1.htm

Organização Mundial da Saúde [OMS] (2002). Relatório mundial sobre violência e saúde. Genebra. Recuperado: 6 out. 2011. Disponível: http://www.opas.org.br/cedoc/hpp/ml03/0329.pdf

Paludo, S., \& Koller, S. H. (2005). Quem são as crianças que estão nas ruas: vítimas ou vitimizadoras? Interação em Psicologia, 9 (1), 65-76.

Placo, V. M. N. S. (2001). Prefácio. Em J. Tavares (Org.), Resiliência e Educação (pp.7-8). São Paulo: Cortez.
Polonia, A. C., Dessen, M. A., \& Silva, N. L. P. (2005). O modelo bioecológico de Bronfenbrenner: contribuições para o desenvolvimento humano. Em M. A. Dessen, \& A. L Costa Júnior (Orgs.), A ciência do desenvolvimento humano: tendências atuais e perspectivas futuras (pp. 71-89) Porto Alegre: Artmed.

Resende, P. (2010). Entrevista com Roberto Carlos Ramos, protagonista do filme o contador de histórias. Cinema em cena. Recuperado: 20 set. 2010. Disponível: http://www.cinemaemcena. com.br/Entrevista_Detalhe.aspx?id_entrevista $=53$

Salvador, C. C., Mestres, M. M., Gõni, J. O., \& Gallart, I. S. (1999). Psicologia da educação. (C. M. Oliveira, Trad.). Porto Alegre: Artes Médicas Sul.

Santos, L. L., \& Dell 'Aglio, D. D. (2006). A constituição de moradas nas ruas como processo de resiliência de adolescentes. Em D. D. Dell 'Aglio, S. H. Koller, \& M. A. M. Yunes (Orgs.), Resiliência e Psicologia Positiva: interfaces do risco à proteção (pp.203-244). São Paulo: Casa do Psicólogo.

Tudge, J. (2008). A teoria de Urie Bronfenbrenner: uma teoria contextualista? Em L. V. C. Moreira, \& A. M. A. Carvalho (Orgs.), Família e educação: olhares da Psicologia (pp.209-231). São Paulo: Paulinas.

Viegas, S. S. (2007). A política de atendimento a crianças e adolescentes em abrigos de Belo Horizonte: história, organização e atores envolvidos. Dissertação de Mestrado, PUC Belo Horizonte, Belo Horizonte-MG. Recuperado: 12 out. 2012. Disponível: http:// www.biblioteca.pucminas.br/teses/Letras_ViegasSS_1.pdf

Vilaça, L. (Diretor). (2009). O contador de histórias [DVD]. Brasil: Warner Bros.

Recebido em: 06/02/2014

Reformulado em: 03/03/2014

Aprovado em: 03/03/2015

\section{Sobre as autoras}

Marluce Auxiliadora Borges Glaus Leão (mgleao08@gmail.com)

Psicóloga, docente do curso de Mestrado em Desenvolvimento Humano: Formação, Políticas e Práticas Sociais da Universidade de Taubaté.

Zilda Regina de Souza (zilda.regina@yahoo.com.br)

Assistente Social, Mestre em Desenvolvimento Humano: Formação, Políticas e Práticas Sociais, Universidade de Taubaté.

Maria Aparecida Campos Diniz de Castro (nenacdiniz@gmail.com)

Pedagoga, docente do curso de Mestrado em Desenvolvimento Humano: Formação, Políticas e Práticas Sociais da Universidade de Taubaté.

A primeira autora se responsabilizou pelo desenho e articulação teórica do texto; a segunda pela produção e formatação e a terceira, pelo planejamento e utilização do material como tecnologia educativa em sala de aula. 